\title{
A CORRELAÇÃO ENTRE OS DIREITOS REPRODUTIVOS E O DIREITO AO TRABALHO A LUZ DOS PRINCÍPIOS DE YOGYAKARTA
}

\author{
Paula Isabel Nóbrega Introine ${ }^{1}$ \\ Marylad Medeiros da Silva ${ }^{2}$
}

\begin{abstract}
RESUMO: O objetivo deste estudo é fazer inter-relação dos direitos reprodutivos da mulher, o mercado de trabalho, os problemas gerados por essa conexão e demonstrar importância dos Princípios de Yogyakarta como instrumentos para promoção e progressão das políticas públicas voltadas a não discriminação e não preconceito nas relações de emprego, decorrentes do direito reprodutivo e da questão de identidade de gênero. Portanto, os resultados avançam no conhecimento dos Princípios de Yogyakarta e como podem ser vetores de promoção social, principalmente quando encarados de forma vinculante, refletindo na vida das pessoas envolvidas, garantindo dignidade, liberdade, igualdade entre homens e mulheres.
\end{abstract}

Palavras-chave: Gênero; Direitos Reprodutivos; Trabalho; Maternidade; Princípios de Yogyakarta.

\section{CORRELATION BETWEEN REPRODUCTIVE AND LABOR RIGHTS IN THE LIGHT OF YOGYAKARTA PRINCIPLES}

\begin{abstract}
The aim of this study is to interrelate the reproductive rights of woman, the labor market, the problems generated by this connection and to demonstrate the importance of the Yogyakarta Principles as instruments to promote advances in public policies of nondiscrimination or prejudice in labor relations due to reproductive right and gender question. Therefore, the results advance on Yogyakarta Principles knowledge and how they can be as vectors of social promotion, mainly when faced in a binding form, reflecting in the life of persons involved, assuring dignity, liberty and equality between men and women.
\end{abstract}

Keywords: Gender; Reproductive rights; Labor; Maternity; Yogyakarta Principles

\footnotetext{
${ }^{1}$ Mestranda em Direito e Desenvolvimento Sustentável pelo Centro Universitário pelo UNIPÊ. Especialista em Direito e Processo do Trabalho (UNIDERP); em Direito Civil (FADISP) e MBA em Segurança e Saúde do Trabalho (FPB). Professora e Advogada.

${ }^{2}$ Mestranda em Direito e Desenvolvimento Sustentável pelo Centro Universitário pelo UNIPÊ. Especialista em Direito Processual do Trabalho (FIP). Professora da Graduação e Pós-Graduação do IESP. Engenheira Civil (UFPB). Servidora do TRT da $13^{\text {a }}$ Região.
} 


\section{INTRODUÇÃO}

Infelizmente ainda se vive em uma sociedade em que as mulheres não possuem a mesma liberdade e igualdade quando comparada aos homens. Apesar de diversas conquistas no cenário legal e social, o percurso histórico de lutas e movimentos demonstra que os direitos aparentemente iguais não condizem com a realidade, pois em muitos povos e culturas as mulheres ainda são vistas como invisíveis.

Uma das características que sempre esteve associada à mulher é a responsabilidade pela reprodução humana, inerente a sua biologia, mas que não pode ser vista como algo qualquer, impositivo. A evolução antropológica e a legal são nebulosas em relação à matéria, sendo algo relativamente recente a sua proteção e qualificação como um direito humano a ser protegido.

Juntamente com essa problemática envolvendo os direitos reprodutivo, há outra relacionada com a discriminação contra a mulher no mercado de trabalho, principalmente quando adicionadas as variantes da maternidade e do trabalho, gerando com isso consequências no âmbito familiar, do trabalho, emocional e pessoal dos indivíduos envolvidos.

Para uma maior proteção é necessário instrumentos que promovam e defendam os direitos humanos relacionados à mulher, à maternidade, ao direito ao trabalho, ao direito reprodutivo, de acordo com a liberdade e a igualdade, sem reduzir capacidades e oportunidades, que repercutem no desenvolvimento humano das mulheres e reflexamente na humanidade como um todo.

Além de convenções e tratados internacionais que visam proteger a mulher contra várias formas de discriminação e desigualdades, evolutivamente surgem princípios humanitários denominados de Princípios de Yogyakarta que vêm para dar maior proteção em relação a qualquer forma de discriminação decorrente de orientação sexual e identidade de gênero. Todavia são poucos difundidos e conhecidos, mais um motivo de ter sido analisado no presente trabalho.

Diante desse cenário vê-se a necessidade de fazer uma inter-relação entre os Princípios de Yogyakarta, os direitos reprodutivos, a mulher enquanto classificação de gênero e o direito ao trabalho, pois tais vetores são importantíssimos ao desenvolvimento sustentável. Com isso, o artigo visa analisar se há como aplicar tais princípios como instrumento de promoção dos referidos direitos e qual o reflexo dessa proteção caso haja. 


\section{A CONQUISTA DO DIREITO REPRODUTIVO PELAS MULHERES}

Ao longo dos séculos as mulheres vêm buscando uma maior igualdade e liberdade perante os homens, onde as características relacionadas à identidade de gênero acompanham as mulheres no período moderno como um ser frágil, dócil, fiel, intelectualmente inferior, que existe para servir e procriar, sendo responsável pelo ambiente interno, ou seja, doméstico.

Esse entendimento vem respaldado à época pelos grandes cientistas, médicos, filósofos e dogmas religiosos, fazendo com que as mulheres fossem sempre consideradas inferiores e subalternas aos anseios de seu dono, o marido ou pai. Retrato da cultura do patriarcado, em que o homem é o responsável por manter seus dependentes e escravos, resolver os problemas e sustentar a família, pois é o mais forte e inteligente.

Juntando essa concepção naturalista, com a antropológica de que o patriarcado vem para substituir o matriarcado da sociedade primitiva, a mulher passa a ser considerada uma mera coisa, em muitos casos sem direito algum, até mesmo o patrimonial, pois a sucessão da propriedade na sociedade patriarcal era de pai para filhos, não fazendo parte a esposa e filhas.

Porém para antropologia nem sempre as mulheres foram subalternas aos homens, inferiores, pois nas sociedades primitivas foi marcada pelo matriarcado, eram as dirigentes da sociedade e da cultura, onde quem possuía o poder de comando eram as mulheres, responsáveis pela produção intelectual, cultural e industrial. A maternidade era vista como algo sublime, um grande dom da natureza e não como um peso a ser suportado (REED, 2008).

Algo interessante que deve ser ressaltado é que nessa sociedade primitiva, apesar da mulher ter o comando da sociedade, não havia problemas relacionados com desigualdades sociais, discriminação ou inferioridades, isto é, não era fundada na opressão do homem, ao contrário fez-se com que esses conseguissem evoluir em seu papel social e cultural. (Ibid)

Porém com o passar dos anos a sociedade trasmuda-se para uma conjuntura patriarcal, juntamente com os direitos patrimoniais, pois a partir desse momento a postura masculina passa a ser outra: o de poder sobre a mulher, onde de fato essa passa a ser um objeto de posse por parte do marido ou pai. Atrelado a isso vem o conceito mais forte de monogamia, pois devido aos direitos sucessórios e patrimoniais, só os homens possuem esse direito, fazendo com que a dependência econômica fosse instransponível.

E assim foi sendo propagado o mito da superioridade masculina, e de que as mulheres são seres inferiores em sua natureza, para muitos condenando a mulher a mera questão da 
maternidade, sendo a natureza o juiz que condenou o sexo feminino a essa posição de inferioridade. (REED, 2008, p. 58).

A sociedade contemporânea atual, que sucedeu essa "antiga" sociedade patriarcal, ainda possui resquícios da sua existência, no que se refere à impotência feminina relacionada à dependência econômica, tanto pela ausência de oportunidade no trabalho como em determinadas culturas pela falta de capacidade, ausência do acesso à educação e saúde.

Especificamente com relação aos direitos reprodutivos e sexuais, só começaram a ser vistos como direitos fundamentais e humanos há pouco tempo, juntamente com as conquistas relacionadas aos direitos humanos das mulheres. Esses direitos tiveram um longo processo, pautado em resistência e lutas por parte dos movimentos feministas.

A primeira menção oficial sobre os direitos reprodutivos, foi em 1968, no Irã, onde previu que os pais têm o direito humano básico de decidir livremente e com responsabilidade sobre o número e o espaçamento de seus filhos. Todavia, o termo "direitos reprodutivos", foi criado por feministas norte-americanas em 1984 no I Encontro Internacional da Saúde da Mulher, na Holanda. Mais adequado do que o termo "saúde da mulher", elevou o conceito para pauta de autodeterminação reprodutiva das mulheres. (MATTAR e DINIZ, 2012, p. 110)

Avançando na caminhada da efetivação dos direitos reprodutivos, em 1994 há uma mudança de paradigma, na Conferência Internacional de População e Desenvolvimento, realizada no Egito, quando a mulher passou a ser vista como sujeito de políticas públicas e não mais como objeto, nos programas de desenvolvimento e população.

Durante décadas, as mulheres foram alvos preferenciais dos programas de controle
populacional e de iniciativas de desenvolvimento centradas em uma perspectiva
masculina. A interferência do movimento populacional na política internacional
sempre teve como único objetivo reduzir o crescimento populacional, com escassa ou
nenhuma preocupação de fato com as mulheres - que eram vistas somente como
objeto de regulação e controle, mesmo sendo os principais sujeitos da atividade
reprodutiva. Já o movimento de mulheres, que também tinha na reprodução um de
seus elementos centrais, focava-se no controle da mulher sobre o seu próprio corpo,
sua sexualidade e vida reprodutiva, em clara oposição à interferência da Igreja e do
Estado em seus corpos. (MATTAR e DINIZ apud CORREA e ÁVILA, 2012, p. 110).

E assim os direitos relacionados ao tema foram progredindo, tanto na esfera internacional quanto nacional. No Brasil somente foram regulamentados em 1996, pela Lei de Planejamento Familiar, Lei $n^{\circ} 9.263$, que vem regular o $\S 7^{\circ}$ do artigo 226 da Constituição Federal. Conforme o artigo $2^{\circ}$, entende-se como planejamento familiar "o conjunto de ações de 
regulação e fecundidade que garante direitos iguais de constituição, limitação ou aumento da prole pela mulher, pelo homem ou pelo casal”. (BRASIL, 1996).

Os direitos reprodutivos abrangem tanto a questão da saúde sexual da mulher, como a questão do planejamento familiar, livre e igualitário, o que permite que as escolhas tomadas pela mulher não sejam objeto de discriminação ou de desigualdade de oportunidades e capacidades, pois como já dito ainda existem resquícios do patriarcado na sociedade, seja ela qual for, tanto as "desenvolvidas" quanto as em "desenvolvimento".

Todavia, não basta previsão em legislação nacional e internacional para que os direitos sejam efetivados, é necessário políticas públicas capazes de eliminar as formas de discriminação e desequilíbrio tanto nas relações familiares quanto nas relações externas. Cabe ressaltar, que não está se falando em políticas de natalidade, mas de programas que atuem contra condutas de desigualdade de gênero decorrente da maternidade, assegurando assim o respeito aos princípios da dignidade da pessoa humana e da liberdade.

Sob o prisma da justiça, também pautada no respeito aos direitos humanos e das liberdades, Bobbio (2004), ao mencionar a dificuldade de concretude de tais direitos, levanta a justificativa de ser um problema jurídico de amplitude política, não de uma mera filosofia, pois não se trata de saber quais são esses direitos, sua natureza ou fundamento, se são naturais ou históricos, absolutos ou relativos, mas sim qual o modo mais seguro para garantir e impedir que esses direitos, previstos em declarações tão solenes, sejam continuamente violados.

A questão do direito reprodutivo, relacionados à maternidade e sua livre escolha, tem maior reflexo sobre a vida das mulheres, pois ainda vivemos em uma sociedade em que há desigualdade tanto no ambiente doméstico quanto no mercado de trabalho, já que o ônus de cuidado é visto como obrigação inerente à mulher, característica atrelada ao gênero feminino, mantendo-as muitas vezes dependentes dos maridos e do Estado.

A discriminação contra a mulher decorrente dos direitos reprodutivos pode ser ainda maior quando essa não tem apoio nem por parte da família, do pai do seu filho ou mesmo pelo poder público, tornando-as ainda mais vulneráveis, colocando-as à margem, e consequente atingindo a própria criança que carecerá de suporte, pois caberá só a mãe a busca pela liberdade necessária para conquistar os bens vitais.

A questão dos direitos reprodutivos ainda vai além da maternidade, por abranger a não maternidade, isto é, a livre escolha por parte da mulher de não querer ter filho, seja utilizando meios contraceptivos ou até mesmo por pleitear o direito ao aborto seguro, tema sempre 
palpitante na sociedade. Isso deve-se a outra característica de identidade de gênero, pois a mulher é vista ainda como reprodutora, e quando opta em não ter filhos é tida como uma conduta suspeita, passando pelo crivo de uma pressão moral.

Decorrente de tal contexto, a comunidade internacional se preocupa com a questões relacionadas a desigualdade de gênero, elaborando diversos documentos que visam protegem a mulher de condutas discriminatórias e que busquem uma maior igualdade por parte dos Estados nos assuntos que envolvam as mulheres e meninas, tanto que é um dos Objetivos do Desenvolvimento Sustentável (ODS) a questão da Igualdade de Gênero.

Todavia, apesar de todas as consequências negativas decorrentes da liberdade do direito de reprodução ou não, e do direito à maternidade sobre a mulher, não foi a natureza, ou seja, a questão da biologia inerente à procriação da espécie, mas sim de acordo com Marx e Engels, a sociedade de classe a responsável pela desigualdade sexual.

Precisamente quando a sociedade comunitária foi derrotada, estas antigas governantas da sociedade foram também derrotadas e isoladas, despertadas e separadas em seus lares solitários, e ficaram limitadas a tarefas sufocantes da cozinha e de cuidar das criadas. (REED, 2008, p. 53)

Assim, de acordo com Marx e Engels, todas as sociedades, tanto as que mencionamos quanto as atuais, têm o fundamento no trabalho, pois para eles a espécie humana não está resumida à capacidade das mulheres de reproduzirem, mas sim como fator decisivo o fato de que a maternidade impulsiona o trabalho, e foi a partir dessa fusão entre a maternidade com o trabalho que nasce o primeiro sistema social. (REED, 2008, p. 61). Diante te tal quadro, necessita-se fazer uma nova análise com relação aos direitos reprodutivos, sua interligação e as consequências no direito ao trabalho.

\subsection{DO TRABALHO REPRODUTIVO AO PRODUTIVO}

Conforme a teoria desenvolvida por Friedrich Engels (1984), a sociedade mudou com o patriarcado, e mais ainda com a família monogâmica. O lar perdeu seu caráter social, passando a mulher a ser sua primeira criada, sem mais fazer parte da produção social.

Para Engels, só a indústria era capaz de abrir de novo, apenas para proletária, o caminho para produção social. Todavia, isso foi feito de uma maneira que se a mulher cumpre os deveres no serviço privado da família, ficará excluída do trabalho social, e de ser 
independente. Da mesma forma aquelas que adentrarem no universo social, e qualquer profissão, será impossível cumprir com as obrigações domésticas. Tanto que as famílias modernas se baseiam na escravidão doméstica da mulher, franca e dissimulada, e a sociedade moderna é uma massa cujas moléculas são as famílias individuais. (ENGELS, 1984).

Na concepção da família moderna o homem tem que ganhar o meio de vida, alimentar a família, o que lhe dá uma posição de domínio, não precisando de lei para determinar isso. Para ele, o homem nessa família é o burguês e a mulher o proletário, enquanto que no mundo industrial a opressão econômica que pesa sobre o proletário não se manifesta em todo o seu rigor senão quando suprimidos todos os privilégios legais da classe capitalista e juridicamente estabelecida a plena igualdade das duas classes. (ENGELS, 1984).

O autor defende que só se conseguirá uma igualdade absoluta, isto é, a mulher só estará liberta, quando houver a reincorporação de todo o sexo feminino à indústria social, sendo necessário uma supressão da família individual enquanto unidade econômica da sociedade. Surge daí uma teoria dos sistemas familiares e da independência feminina, pois ao argumentar que a família leva a mulher à escravidão, então seria melhor ela não casar, algo que não pesa pelo senso de justiça ou em tentar solucionar esse abismo cultural que não consegue se sobrepor.

Tanto que, de acordo com Sen (2010b, p. 25) para que se argumente que um sistema familiar particularmente desigual e sexista é injusto, não é necessário demonstrar que as mulheres ficariam melhor se não tivesse família alguma, bastaria demonstrar que a divisão dos benefícios naquele sistema é seriamente desigual. Assim,

[...] é a naturalização dessa divisão sexual das tarefas domésticas, reproduzida socialmente graças a presença de uma construção patriarcal, que segue reproduzindo o capitalismo e a exploração da força-de-trabalho da classe trabalhadora, mediante sua invisibilização política, social e econômica. (FURNO, 2015).

Os primeiros debates sobre essa espécie de desigualdade tiveram seu processo interligado à industrialização, entre os séculos VIII e XIX, quando a produção orientada para o mercado estava se dissociando da doméstica, autoconsumo familiar, o que iria se consolidar com a implantação do capitalismo. Para pensadores clássicos a preocupação com o sistema capitalista e os tipos de produção que relacionavam o trabalho e a distribuição de renda com aspectos da produtividade, eficiência, salário, divisão do trabalho e o trabalho era visto como emprego e nunca como produção realizada no ambiente doméstico. (TEIXEIRA, 2008). 
Para Adam Smith, a atividade das mulheres em casa, destinada a cuidar da família é muito importante, posto que a educação e cuidados com os filhos influenciava para que se transformassem em trabalhadores produtivos e contribuíssem para a criação das riquezas. Constatando que as mulheres tinham a obrigação primeira de ser mãe e esposa, o que se tornaria incompatível com o emprego fora de casa. (TEIXEIRA apud PUJOL, 2008).

Nascendo e prosperando a cultura de que o homem nasceu para produção e a mulher para reprodução, na era do capitalismo e do livre mercado, os homens estão para o trabalho assalariado e a mulher para os serviços domésticos, baseado em princípios como o da separação e o da hierarquização do trabalho. Ademais, o valor do trabalho desenvolvido pelo homem é sempre mais valorizado. (FURNO, 2015).

Tanto que com a evolução do capitalismo e a permanência dos preconceitos relacionados a questão de gênero, as mulheres que entravam no mercado de trabalho, assumiam profissões ditas femininas, como a enfermagem e as voltadas à educação, por considerar que as mulheres não possuíam intelecto suficiente para desempenhar profissões que não estivessem relacionadas com a "natureza" feminina.

Os salários pagos às mulheres não deveriam ser elevados, mas sim o necessário para sua subsistência, cabendo sim ao homem receber salário que pudesse sustentar a si, a uma mulher e um número adequado de filhos. Ou seja, os homens a época não eram contra que as mulheres trabalhassem, mas que elas ganhassem dinheiro, para assim não puderem ter acesso a qualquer poder social e econômico. (CARRASCO, 2008).

Nesse caminho percorrido pelas mulheres da reprodução à produção, de acordo com a teoria marxista sobre trabalho produtivo e improdutivo, as atividades domésticas desempenhadas pelas mulheres não eram consideradas produção, pois não gerava riqueza, mais valia. Havia, portanto, uma hierarquia do valor social deste trabalho, sendo o trabalho doméstico infinitamente inferior ao trabalho externo, produtivo. (TEIXEIRA, 2008).

Em contrapartida, existe teoria que defende as atividades domésticas como trabalho, porque há uma relação entre economia individual e social, reconhecendo a casa como centro de produção. Para ela, para que essa estrutura antiga desenhada em que a mulher é responsável pelos serviços domésticos, apenas, deve ser refeita, parte das atividades desempenhada por elas deve ser delegada, com a finalidade de que possuam mais tempo para se dedicarem ao trabalho. (TEIXEIRA, 2008). 


\section{A DESIGUALDADE NO MERCADO DE TRABALHO DECORRENTE DO DIREITO REPRODUTIVO}

O avanço das conquistas femininas sempre está acompanhado de políticas públicas não eficazes, pois apesar de hoje a realidade da mulher no mercado de trabalho ser bem diferente do início da história, ainda é corriqueiro e comum condutadas discriminatórias no seio laboral, desde salários inferiores até demissões, passando por problemas relacionados a assédio moral e condutas discriminatórias pautadas em identidade de gênero, como no caso da maternidade.

O direito reprodutivo, apesar de constitucionalmente estabelecer ser obrigação de ambos os pais a responsabilidade sobre os cuidados com a criança, ainda dar-se à mulher o maior peso sobre essa responsabilidade, atrelando sempre a questão de características de gênero, ditas como naturais, porém que ensejam condutas e situações desiguais e discriminatórias.

Em contrapartida, o homem é visto de forma positiva pela sociedade, pois o fato desse ser casado e ter filhos é associado com uma maior responsabilidade e dedicação ao trabalho, enquanto para as mulheres os filhos são vistos como circunstância que irá dificultar a produção e a dedicação que elas darão ao trabalho.

Nessa visão o trabalho sempre está em segundo plano, enquanto que família, por uma circunstância natural, é prioridade e responsabilidade dela, o que faz com que de fato muitas mulheres abandonem o mercado de trabalho, ou se dediquem de forma parcial, ou mesmo substituía por um trabalho informal. (BARHAM e VANALLI, 2012).

Isto é, as normas socioculturais permitem que a maioria dos homens assuma menos reponsabilidades familiares e disponham de mais tempo do que as mulheres para investirem na carreira. Gerando com isso uma situação de menos expectativa e de satisfação por parte das mulheres quando comparadas com os homens.

\footnotetext{
Os referidos limites se traduzem em discriminação e, por eles, a mulher se vê impedida de "sair para o mundo", por assim dizer. E quando sai, quando busca e, em consequência, acumula funções (considerando maternidade, família e profissão), a mulher ganha os limites da desvalorização e da incredibilidade, com total desprezo às disposições constitucionais já existentes e que têm por objetivo o resguardo aos direitos conferidos a todos, a si especificamente e ao seu trabalho. (MAGALHÃES e KESROUANI, 2016, p. 330).
}

Cabe mencionar estudo realizado sobre a matriz da desigualdade social na América Latina, onde dados estatísticos foram analisados na seara do acesso à educação e ao trabalho, 
constatando que as mulheres não conseguem o mesmo acesso que os homens, mesmo quando mais qualificadas, com maior nível de escolaridade, o que caracteriza a discriminação de gênero no mercado de trabalho.

Entre los adultos (30 a 59 años) se repite el mismo patrón, aunque las tasas de desempleo sean significativamente inferiores em todos grupos considerados: la tasa de desempleo de las mujeres afrodecendientes sigue siendo muy superior a la de los hombres no afrodecendientes (2,3 veces em el Brasil y 3,8 veces el Uruguay). También em este tramo de edad, las mujeres tienen mayores níveles de escolaridade que sus pares varones, pero esto no contribuye a reducir sus tasas de desempleo. (ABRAMO, 2016, p. 24).

A discriminação de gênero no mercado de trabalho é algo cultural em nossa sociedade brasileira e na seara mundial, uns países mais e outros menos. Porém a mulher ainda é subvalorizada e estereotipada no universo trabalhista, estereótipos como sexualidade, incapacidade, fraqueza, sensibilidade, dentre tantos outros são sempre características femininas ditas como empecilho para assumir cargos de importância ou ter acesso a uma vaga de trabalho, relacionando questões ligadas ao gênero para realizar condutas discriminatórias.

São vários os fatores de discriminação, mas um dos mais sensíveis por atingir tantos princípios constitucionais, trabalhistas e humanos é a diferenciação pautada na mulher possuir o direito à maternidade, de se tornar mãe, de constituir uma família, de realmente ter a liberdade do direito reprodutivo, escolhendo o momento que quer ter filhos e não os desconsiderar por sofrer discriminação no trabalho.

Estudo realizado em Harvard (RIVERA e TILCSIK, 2016) revelou em dezembro de 2016 dados alarmantes, o artigo Research: How subtle class cues can backfire on your Resume tinha a princípio analisar se haveria discriminação na seleção de estagiários do curso de Direito pelo fato desses pertencerem a classes sociais diferentes, mesmo possuindo idêntica formação e prestígio acadêmico. Foram enviados 4 currículos para 316 escritórios das 147 melhores firmas de advocacias, em 14 cidades diferentes, mas o que mais saltou aos olhos dos pesquisadores foi que o currículo mais selecionado foi o do homem de classe alta, onde este foi selecionado 4 vezes mais do que o currículo da mulher da mesma classe social, fato que demonstra a discriminação de gênero latente da seleção.

Todavia não para por aí, um dos principais motivos levantados pelos advogados entrevistados é que a mulher se desvirtuaria na sua carreira por causa da família e da maternidade, principalmente se esta tivesse já uma melhor condição social, por isso nem 
selecionadas para entrevistas foram. Enquanto para o sexo masculino ambas as características são positivas, ser de família de classe alta e não ter a família como um empecilho na sua carreira.

Outro artigo, também do ano de 2016, publicado pela revista American Sociological Review (ENGLAND, BEARAK, BUDIG e HODGES, 2016), reforça a ideia da cultura de discriminação da mulher no mercado de trabalho pelo fato da maternidade, onde afirmam diante de análises estatísticas que ter um filho é ruim para carreira de uma mulher, principalmente se ela for altamente qualificada e remunerada.

A pesquisa mostra que a empregada pode sofrer uma perda salarial de até $10 \%$ por filho, tendo a autora denominado tal situação de "penalidade da maternidade", que faz com que as mulheres mais bem qualificadas optem em não sair do mercado de trabalho ou não ter filhos, para assim não sofrer danos na carreira profissional. Demonstrou-se que apenas $4 \%$ do total das mães que optam em ficar em casa para cuidar dos filhos, são formados por mulheres altamente qualificadas e remuneradas, decorrência da tão temida penalidade da maternidade.

Contudo, apesar de toda discriminação enfrentada no mercado de trabalho e também dos problemas que as mulheres passam no ambiente doméstico, por assumir dupla ou tripla jornada, o trabalho remunerado representa uma maior autonomia e independência econômica na vida adulta, trazendo consigo um reconhecimento social e pessoal, onde a ampliação do conhecimento, e maiores contatos sociais, conduzem à formação de uma identidade profissional e sentimento de utilidade. Dessa forma, aumenta o senso de competência, melhorando a autoestima, repercutindo positivamente dentro do ambiente familiar. (D’AFFONSECA, 2005).

Outro fato importante é o da segregação profissional por gênero. Refere-se às desigualdades na distribuição de homens e mulheres em diferentes categorias profissionais, apesar de existirem diversas teorias econômicas que versam sobre o tema, como o do capital humano, da discriminação e da discriminação estatística. Porém não explicam as origens do preconceito no mercado de trabalho, simplesmente assumem que ele existe. Assim, a segregação das mulheres em profissões não ocorre como consequência de escolhas, mas por influência de estereótipos e discriminação estatística dos empregadores. (TEIXEIRA, 2008).

As lutas contra a depreciação das capacidades produtivas da mulher e sua marginalização em setores do trabalho remunerado evidenciam tanto o embricamento entre a reprodução material e simbólica da sociedade, quanto os efeitos economicamente perversos da condição de não reconhecimento. Honneth, assim, vincula mais uma vez as demandas redistributivas a experiências de injustiça verificadas em relações assimétricas de reconhecimento. Trata-se aqui, entretanto, não mais da reivindicação por um "mínimo de bens essenciais garantidos a cada cidadão independentemente de sua produção", mas de exigências de reconhecimento pelo 
trabalho efetivamente realizado por grupos sociais específicos e produtivamente ativos. Nesse sentido, a luta contra as diferentes formas de exploração e marginalização do trabalho - levadas a cabo não apenas pelo movimento de mulheres como pela maior parte dos grupos que lutam atualmente pelo reconhecimento de suas capacidades produtivas - exige a transformação dos padrões valorativos tradicionais envolvidos na distribuição desigual de remuneração e status. (RAMOS, MELO e FRATESCHI, 2012, p. 294).

Os avanços legais acompanham as conquistas femininas, como também o progresso dos entes internacionais que tentam defender os direitos humanos da mulher, pois estes, de acordo com Bobbio (2004), não nascem todos de uma vez e nem de uma vez por todas, avançam com base nos proclames sociais e com a necessidade defesa naquele momento de determinados direitos, o que não impede que novos direitos venham a serem proclamados em outra situação como direitos humanos, construindo-os e reconstruindo-os.

Considerando a historicidade destes direitos e a concepção contemporânea deles, que foi introduzida com a Declaração Universal de 1948 e reiterada pela Declaração de Viena de 1993, essa concepção é decorrência da internacionalização dos direitos humanos, surgido a partir do pós-guerra, onde o cenário desenhava-se o esforço de reconstrução dos direitos humanos, como paradigma e referencial ético a orientar a ordem internacional contemporânea. (PIOVESAN, 2006).

Dessa forma os direitos humanos são uma categoria de direitos indivisíveis, interdependentes, inter-relacionados, capaz de conjugar os direitos civis e políticos, sociais, econômicos e culturais. Juntamente com eles, encontram-se os valores relacionados à democracia e o desenvolvimento, pois não há como garantir os direitos humanos sem que seja em uma sociedade democrática, incluindo de forma concreta todos os grupos vulneráveis, como enaltecido pela Convenção de Viena de 1993. (PIOVESAN, 2006).

A importância do tema é tamanha devido ao processo constante de violação de direitos dos grupos sociais mais frágeis, como é o caso das mulheres e da população negra, surgindo daí os fenômenos da "feminização" e "etnização" da pobreza, pois de acordo com dados, se o mundo hoje há um bilhão de analfabetos adultos, 2/3 deles são mulheres. (PIOVESAN, 2006).

Com isso, verifica-se a necessidade de políticas públicas não apenas de caráter universalista, mas endereçadas aos grupos mais vulneráveis, por serem vítimas mais propensas a exclusão, indo além de uma igualdade formal, adentrando nas diferenças, nas peculiaridades e especificidades de cada integrante desse grupo, como o caso das mulheres.

Sob esse aspecto de exclusão Sen (2010) faz a ponderação que mesmo que haja a preocupação em estabelecer políticas públicas que visem incluir estes excluídos, não se deve 
seguir para um processo de inclusão injusta, isto é, apesar do sujeito não estar fora do ambiente ou direito social, este é aplicado de forma injusta e muitas vezes desumanas, como por exemplo o trabalho escravo ou condições degradantes.

\begin{abstract}
A conclusão básica é que precisamos estar conscientes dos dois tipos de injustiça - da exclusão injusta e também da inclusão injusta - e não devemos confundir as duas. Da forma como ocorrem, muitos dos casos mais extremos de violação dos direitos humanos, como a negação às liberdades básicas, tortura, prisão sem julgamento, privação de direito de votar, por um lado, e fome ou ausência completa de cuidados médicos, por outro, podem muito bem ser discutidos dentro do formato da "exclusão". Devemos, porém, abrir espaço também para aquelas violações dos direitos humanos que incluem trabalho escravo, trabalho exaustivo, semiescravidão infantil, problemas ambientais etc., que são mais bem encaixados na categoria de inclusão injusta. (SEN, 2010, p. 37)
\end{abstract}

Os direitos humanos contemporâneos tentam avançar no combate a qualquer tipo de discriminação e desigualdade, indo além até da igualdade material clássica, baseada em critérios de justiça social e distributiva, passando por uma igualdade material com o reconhecimento de identidades, como o caso da igualdade baseada nos critérios de gênero, orientação sexual (PIOVESAN, 2006).

Diante disso, recomendações e normas internacionais, bem como estudos desenvolvidos são necessários para esse progresso, especificamente sobre a questão de identidade de gênero e orientação sexual, neste cenário encontra-se um importante documento, os Princípios de Yogyakarta.

\title{
4 OS PRINCÍPIOS DE YOGYAKARTA E SEUS REFLEXOS NOS DIREITOS REPRODUTIVOS E AO TRABALHO.
}

É importante que a comunidade internacional se solidarize cada vez mais com os grupos sociais que mais carecem de atenção e cuidado, por serem sujeitos de condutas excludentes ou de uma inclusão injusta, como as mulheres, que dentro de uma conjuntura conceitual de identidade de gênero lá se encontram.

No intuito de uma maior efetividade das normas já existentes sobre o tema, bem como por saber que ainda é comum a violação dos direitos humanos pautado nas questões de gênero e orientação sexual, em novembro de 2006, na cidade de Yogyakarta, Indonésia, um grupo de conceituados especialistas em direitos humanos prepararam documento, definindo os Princípios 
de Yogyakarta sobre a Aplicação da Legislação Internacional de Direitos Humanos em relação à Orientação Sexual e Identidade de Gênero. (YOGYAKARTA PRINCIPLES, 2007).

Tais princípios tem o intuito de estabelecer um futuro diferente, onde todas as pessoas, que nasceram livres e iguais em dignidade e direitos, poderão exercer esses direitos sem nenhum empecilho quanto a condutas discriminatórias ou preconceituosas no que se refere as questões de identidade de gênero e orientação sexual.

Esse tipo de iniciativa é necessária, pois a violação dos direitos desses grupos está presente em todo o mundo de forma enraizada, ocasionando violações aos direitos humanos, com assassinatos, torturas e maus tratos, agressão, estupro, violação da privacidade, negação de oportunidade de emprego e educação e grave discriminação ao gozo desses direitos. (YOGYAKARTA PRINCIPLES, 2007).

Apesar da Organização das Nações Unidas (ONU) terem criado normativas contra qualquer forma de discriminação baseada em orientação sexual e identidade de gênero, não estão sendo de fato efetivadas, tendo resultados fragmentados e inconsistentes. Por isso foram criados os Princípios de Yogyakarta, com o intuído de explicar e compreender o regimente jurídico internacional pré-existente.

Esses princípios cobrem uma gama de direitos humanos relacionados às questões de gênero e orientação sexual, desde aspectos relacionados à segurança humana e pessoal como os de caráter social, econômico e cultural, a exemplo da educação, saúde e o emprego. Com isso, ratifica-se a obrigação dos Estados signatários, dentre eles o Brasil, de implementar os direitos humanos, recomendando-se o mínimo a ser implementado para sua efetividade.

$\mathrm{O}$ artigo trata especificamente sobre a questão do gênero, uma vez que analisa a discriminação e o preconceito decorrente do direito reprodutivo da mulher no mercado de trabalho. Como os Princípios de Yogyakarta abordam a identidade de gênero e a orientação sexual, cabe primeiramente abordar o que se entende por identidade de gênero, que pode ser definida como aquilo que identifica e diferencia os homens das mulheres.

Todavia, tanto nas ciências sociais como na psicologia, o gênero é entendido como aquilo que diferencia socialmente as pessoas, levando em consideração os padrões históricoculturais atribuídos aos homens e mulheres, é aí que a temática deste trabalho se aproxima.

Ao analisar as questões do direito reprodutivo, na história e antropologia ligados ao assunto, faz com que a identidade de gênero consista no modo como determinado indivíduo se identifica na sociedade, com base no papel social do gênero e no sentido de identidade da 
pessoa. Apesar de existirem várias formas de se classificar essa identidade, esse trabalho analisa apenas a questão da mulher que possui o sexo biológico feminino, independente da sua orientação sexual.

O mais importante é utilizar o conceito de identidade de gênero que leve em consideração os atributos que o indivíduo possui, decorrente de indicações do papel social de gênero, baseado nas variedades da estrutura social, incluindo o trabalho, a religião e a família, onde o gênero é relacionado com significados sociais, culturais e históricos associados aos sexos.

Os Princípios de Yogyakarta têm o intuito de dar maior peso às questões que envolvem identidade de gênero e orientação sexual, pois é necessário uma visão solidária sobre o assunto, pois só quando visto como valores que devam ser protegidos, por versar sobre tema tão importante aos direitos humanos, é que se conseguirá progredir no que diz respeito a preconceito e desigualdade.

Ao todo eram 29 princípios, porém em novembro de 2017 houve a edição do Yogyakarta Principles Plus 10 (YP + 10) (YOGYAKARTA PRINCIPLES, 2017), que complementa os iniciais envolvendo diversos temas. Os princípios 1 a 3 descrevem o princípio da universalidade dos direitos humanos e sua aplicação a todas as pessoas sem discriminação, bem como o direito de cada pessoa ser reconhecida perante a lei. Os princípios 4 a 11 abordam direitos relacionados à segurança humana e pessoal. Os 12 a 18 estabelecem os direitos econômicos, sociais e culturais, como a não discriminação no emprego, à seguridade social e aos serviços de saúde. Já os 19 a 21 sublinham os direitos de expressão, opinião e associação.

Destacam os direito das pessoas à liberdade de circulação e direito de receber asilo (princípios 22 e 23). Direito de participar da vida cultural e familiar tem previsão nos princípios 24 a 26, enquanto o 27 reconhece os direitos dos defensores dos direitos humanos. Os princípios 28 e 29 ratificam o direito a remédios legais e reparações e responsabilidade criminal.

Com os novos princípios adicionados em 2017, somam-se 38 princípios, que versam respectivamente sobre (30 ao 38): Direito à Proteção do Estado; Direito ao Reconhecimento Legal; O Direito à Integridade Corporal e Mental; Direito à Liberdade contra a Criminalidade e a Sanção; Direito à Proteção da Pobreza; Direito ao Saneamento; Direito ao gozo dos Direitos Humanos em Relação às Tecnologias da Informação e da Comunicação; Direito à verdade e o Direito de Praticar, Proteger, Preservar e Reviver a Diversidade Cultural. (YOGYKARTA PRINCIPLES, 2017). 
Especificamente sobre o tema abordado, os Princípios de Yogyakarta são de extrema importância por reforçar a questão das políticas públicas necessárias para combater a discriminação e a desigualdade decorrente da identidade de gênero. Dentre eles há de se destacar o 12 (Direito ao Trabalho); o 24 (Direito de Constituir uma família) e o 30 YP+10 (Direito à Proteção do Estado).

$\mathrm{O}$ artigo analisa exatamente a interligação entre o direito reprodutivo e o direito ao trabalho com o manto dos direitos humanos, em especial os Princípios de Yogyakarta, pois ao tratar da questão de gênero, envolve as características impostas pela sociedade e pelo percurso histórico das mulheres no que diz respeito à maternidade, colocando-as como responsáveis pelos cuidados dos filhos e da família, escusando os homens de tal obrigação. Diante desse fato nasce uma nova discriminação, o do livre acesso ao mercado de trabalho ou mesmo nele se manter, tudo decorrente de estereótipos ditos femininos, de uma divisão sexual do trabalho, seja reprodutivo ou produtivo.

Cabe analisar cada um dos Princípios de Yogyakarta responsáveis pela amplitude dessa proteção, abordando o aspecto reprodutivo, familiar, humano e do trabalho, isto é, perpassando pelos direitos ligados à liberdade, à igualdade e à fraternidade. São eles:

\footnotetext{
Princípio 12: Direito ao Trabalho: Toda pessoa tem o direito ao trabalho digno e produtivo, a condições de trabalho justas e favoráveis e à proteção contra o desemprego, sem discriminação por motivo de orientação sexual ou identidade de gênero. [...] Princípio 24: Direito de Constituir Família: Toda pessoa tem o direito de constituir uma família, independentemente de sua orientação sexual ou identidade de gênero. As famílias existem em diversas formas. Nenhuma família pode ser sujeita à discriminação com base na orientação sexual ou identidade de gênero de qualquer de seus membros. (YOGYAKARTA PRINCIPLES, 2007).

Princípio 30 (YP + 10): O Direito à Proteção do Estado: Todos, independentemente da orientação sexual, identidade de gênero, expressão de gênero ou características do sexo, têm direito à proteção do Estado contra a violência, a discriminação e outros danos, seja por funcionários governamentais ou por qualquer indivíduo ou grupo.
}

O princípio 12 é claro ao reafirmar a proteção ao trabalho justo e digno, da proteção ao desemprego, longe de qualquer espécie de discriminação, esse preceito é importantíssimo que seja reforçado em todas as políticas públicas nacionais e internacionais, pois o trabalho é um dos principais meios de libertação e empoderamento, capaz de ampliar as capacidades e as oportunidades por aqueles que o tem.

Juntamente com o princípio 12 deve ser analisado o 24, pois o intuito do artigo é demonstrar essa inter-relação entre o trabalho e o direito reprodutivo, com base nos Princípios de Yogyakarta e nas políticas direcionadas à igualdade pautada na identidade de gênero. É 
notório o alto grau de preconceito enfrentado pelas mulheres no ambiente de trabalho, principalmente quando associado a características ditas de gênero, como a falta de comando, a sensibilidade excessiva, a maternidade, a prioridade que sempre dará a família, e tantas outras que faz com que elas tenham maior dificuldade de entrar no mercado ou mesmo permanecer.

De acordo com estudos, a maternidade influencia a disputa por vagas ou cargos no ambiente de trabalho, existindo a certeza que também é fator de eliminação ou restrição à cargos ou discriminação. Tal resultado foi confirmado por gestoras entrevistadas onde uma delas afirmou que a empresa onde trabalha não são contratadas mulheres por medo de gestão, afastamento, onerosidade da empresa. Concluindo, as mulheres da pesquisa asseveram que a maternidade é um dos grandes obstáculos que as afasta das oportunidades. (SEGGIARO, 2017).

Essa conexão entre o direito de constituir uma família (princípio 24) e o direito ao trabalho digno, livre de discriminação (princípio 12), encontra-se atrelado o direito reprodutivo, dentre eles o de querer ou não ser mãe e em que momento ser. Infelizmente há discriminação de gênero presente no mercado de trabalho e em específico a decorrente do direito à maternidade e ao direito reprodutivo.

Também faz surgir diversos outros problemas ligados à saúde da mulher, pois o mercado faz com que muitas vezes opte em adiar a gestação por dar preferência ao trabalho, fazendo com que tenham filhos após os 40 anos, o que pode gerar mais riscos para a mulher, ou mesmo terem que fazer tratamento para engravidar ou congelar óvulos. Grande parte dessas escolhas está relacionada com a prioridade que tem que dar ao trabalho, pois uma gravidez poderá seriamente impedir sua evolução profissional.

Os Princípios de Yogyakarta fazem as recomendações atreladas a cada um deles. No que diz respeito ao Direito ao Trabalho (princípio 12), devem os Estados adotar medidas legislativas, administrativas e outras necessárias para eliminar e proibir a discriminação em razão da identidade de gênero e orientação sexual no emprego público e privado, incluindo treinamento profissional, contratação, promoção, demissão, condições de trabalho e remuneração. (YORGYAKARTA PRINCIPLES, 2007).

Tais recomendações realmente trazem temas que devem ser perseguidos com políticas públicas eficazes, no caso do objeto de análise desse artigo, as mulheres, elas sofrem discriminação antes, durante e após as relação de emprego, sendo vítimas de discriminação e preconceito nas seleções de emprego, de assédio moral e discriminação durante e de desigualdades após sua saída, infelizmente um problema complexo, mas que deve ser uma das 
prioridades dos programas que visem uma melhoria na qualidade de vida da população bem como na busca por um desenvolvimento humano.

Quanto ao direito de formar uma família (princípio 24), recomenda-se que os Estados adotem todas as medidas legislativas e administrativas e outras necessárias para garantir o direito de criar uma família, inclusive através da adoção ou à reprodução assistida. Também sugere a criação de leis e políticas que reconheçam as diversas formas de família e garantir que nenhuma família seja discriminada, inclusive no que se refere ao bem-estar social e outros benefícios relacionados à família e ao trabalho. (YOGYAKARTA PRINCIPLES, 2007)

Por fim o princípio $30(\mathrm{YP}+10)$, reforça a necessidade da presença do Estado nas questões que envolvam condutas discriminatórias envolvendo a questão de gênero. Para isso deve-se fazer diligências adequadas para prevenir, investigar, punir e providenciar remédios para discriminação, violência e outros danos cometidos por atores estatais ou não. Juntamente deve tomar medidas para erradicar qualquer forma de discriminação e danos, juntar estatísticas e pesquisas sobre a extensão, causas e efeitos da discriminação, e demais políticas públicas necessárias à promoção dos direitos humanos e à eliminação do preconceito.

Avançando o pensamento sobre a questão de gênero e o trabalho, e vendo a mulher empoderada como um dos vetores necessários para o desenvolvimento econômico sustentável, a própria ONU afirma que não há como conseguir chegar aos ODS sem que haja um progresso na igualdade de gênero, pois:

O grande alcance da condição de agente das mulheres é uma das áreas mais negligenciadas nos estudos sobre o desenvolvimento e requer correção urgente. Podese dizer que nada atualmente é tão importante na economia política do desenvolvimento quanto um reconhecimento adequado da participação e da liderança política, econômica e social das mulheres. Esse é, de fato, um aspecto crucial do "desenvolvimento como liberdade". (SEN, 2010a).

Diante disso vê-se que os Princípios de Yogyakarta é um dos instrumentos que deve ser utilizado na busca dessa igualdade, indo além, tentado atingir políticas públicas fraternais e solidárias, que envolvam não só os Estados signatários, mas sim toda a comunidade mundial, pois o problema está presente em todos os tipos de nações e economias. Devendo ser visto com muita seriedade e reponsabilidade a discriminação enfrentada pelas mulheres decorrente do direito reprodutivo e da maternidade, gerando consequências não só no mercado de trabalho, mas na família, na sua vida pessoal, e consequentemente em toda a sociedade. 


\section{CONCLUSÃO}

A questão da discriminação das mulheres envolvendo características de gênero atingem diversos setores que essa perpassa, desde o ambiente familiar até o ambiente externo (mercado de trabalho), e quando se soma com os direitos relacionados à maternidade, esses problemas sociais se agigantam. Por isso que os Princípios de Yogyakarta são importantes para promoção desses direitos, pois prevê expressamente o direito ao trabalho e a família como princípios inerentes a pessoa humana, e reforça em recomendações o que os Estados devem fazer para tentar eliminar qualquer espécie de desigualdade e discriminação envolvendo o tema.

Como visto, a problemática infelizmente não é algo deste século, ao contrário, a mulher vem seguindo um percurso histórico de muitas lutas, mas mesmo conseguindo uma certa igualdade formal, em diversos Estados, e de normas internacionais que visam a não discriminação da mulher e o combate à violência de gênero, não está sendo suficientemente eficazes. Por isso a importância dos Princípios de Yogyakarta, para reforçar na comunidade internacional os assuntos que envolvem identidade de gênero e orientação sexual, de forma discriminatória e preconceituosa, que devem ser rechaçados, por ferir direito humanos básicos.

Os princípios, reafirmam as normas internacionais já existentes sobre o tema, exigindo uma conduta vinculante de todos, pois caso se consiga internalizar todas as recomendações dadas aos Estados, estar-se-á mais perto de um futuro diferentemente, em que todas as pessoas, que nasceram livres e iguais em dignidade e direitos, possam de fato utilizá-los.

\section{REFERÊNCIAS BIBLIOGRÁFICAS}

ABRAMO, Lais et al. La matriz de la desigualdad social en América Latina. Santiago: CEPAL, 2016, pp. 21-42.

BARHAM. E. J.; VANALLI, A. C. G. Trabalho e Família: Perpectivas Teóricas e Desafios Atuais. Revista Psicologia: Organizações e Trabalho. Jan-abr 2012, p. 47-60.

BOBBIO, Noberto. A Era dos Direitos. Rio de Janeiro: Elsevier, 2004.

BRASIL. Lei ${ }^{\circ}$ 9.263, de 12 de janeiro de 1996. Trata do planejamento familiar, estabelece penalidades e dá outras providências. Disponível em < http://www.planalto.gov.br/ccivil_03/leis/L9263.htm>. Acesso em: 14 fev. de 2018.

CARRASCO, Cristina. La economia feminista: una apuesta por otra economía. In: VARA, Maria Jesús (Coord.). Estudios sobre género y economía. Madrid: Akal, 2008. 
D'Affonseca, S. M. Importância do envolvimento materno para o autoconceito e desempenho acadêmico das crianças de baixo nível socioeconômico. Dissertação de mestrado não publicada. Universidade Federal de São Carlos, São Carlos, SP. 2005.

ENGELS, F. A Origem da Família, da Propriedade Privada e do Estado. 9. ed. Rio de Janeiro: Civilização Brasileira, 1984.

ENGLAND, P.; BEARAK, J.; BUDIG, M. J.; HODGESD, M. J. Do Highly Paid, Highly Skilled Women Experience the Largest Motherhood Penalty? American Sociological Review, v.81, p.1161-1189. 2016.

FURNO, J. da C.. O Trabalho das Mulheres: entre a produção e a reprodução social. 2015. Disponível <https://www.ifch.unicamp.br/formulario_cemarx/selecao/2015/trabalhos2015/Juliane\%20Fu rno\%209600.pdf>. Acesso em: 18 fev. 2018.

MAGALHÃES, V. T.; KESROUANI, S. A igualdade de direitos entre os gêneros e os limites impostos pelo mercado de trabalho à ascensão profissional das Mulheres. XXV Encontro Nacional do CONPEDI: Brasília, 2016.

MATTAR, L. D.; DINIZ, C. S. G. Hierarquia reprodutivas: maternidade e desigualdade no exercício de direitos humanos pelas mulheres. Interface-Comunicação, Saúde, Educação. v.16, n.40, p.107-119, jan./mar. 2012b.

PIOVESAN, F. Direitos humanos: desafios da ordem internacional contemporânea. Direitos humanos, v. 1, p. 15-37. 2006.

RAMOS, F. C.; MELO, R.; FRATESCHI, Y. Manual de Fiolosofia Política: para os cursos de teoria do Estado, e ciências política, filosófica e ciências sociais. São Paulo: Saraiva, 2012.

REED, E. Sexo contra sexo ou classe contra classe. São Paulo: Instituto José Luis e Rosa Sundermann, 2008b.

RIVERA, L.; TILCSIK, A. Research: how subtle class cues can backfire on your resume. Harvard Business Review, 2016.

SEGGIARO, F. B. Mulheres no Mercado de Trabalho: Análise das dificuldades de gênero enfrentadas pelas mulheres do século XXI. Revista Metodista de Administração do Sul, v.2, n. 2, 2017.

SEN, A. Desenvolvimento como Liberdade. São Paulo: Companhia das Letras, 2010a.

; KLIKSBERG, Bernardo. As pessoas em primeiro lugar: a ética do desenvolvimento e os problemas do mundo globalizado. São Paulo: Companhia das Letras, 2010b.

TEIXEIRA, M. O. Desigualdades Salariais entre homens e mulheres a partir de uma abordagem de economistas femininas. Revista Gênero. Niterói, v.9, n.1, p. 31-45, 2. sem. 2008. 
YOGYAKARTA PRINCIPLES. THE YOGYAKATA PRINCIPLES, 2007 Disponível em: <http://yogyakartaprinciples.org/wp-content/uploads/2016/08/principles_en.pdf> Acesso em: 08 out. 2017.

THE YOGYAKATA PRINCIPLES, 2017. Disponível em: <http://yogyakartaprinciples.org/wp-content/uploads/2017/11/A5_yogyakartaWEB-2.pdf>. Acesso em: 15 dez. 2017. 